\title{
Fixed points for mappings defined on generalized gauge spaces
}

\author{
MitRofAN M. CHOBAN
}

\section{ABSTRACT.}

In this article, the distinct classes of continuous pseudo-gauge structures and pseudometrics (perfect, quasiperfect, sequentially complete) are defined and studied in depth. The conditions under which the set of fixed points of a given mapping of a space with concrete pseudo-gauge structure is non-empty are determined. Some examples are proposed.

Acknowledgements. The author is grateful to the Referee for the valuable suggestions and comments.

\section{REFERENCES}

[1] Antonovskii, M. Ja., Boltjanskii, V. G. and Sarymsakov., T. A., A survey of the theory of topological semifields, Uspehi Mat. Nauk 21 (1966), No. 4, 185-218 (in Russian) (English translation: Russian Math. Surveys 21 (1966), No. 4, 163-192)

[2] Beckenstein, E., Narici, L. Suffel, C., Topological Algebras, North Holland Publ. Com., New York, 1977

[3] Berinde, V., Generalized contractions in $\sigma$-complete vector lattices, Univ. u Novom Sadu, Zb. Rad. Prirod.-Mat. Fak. Ser. Mat., 24 (1994), No. 2, 31-38

[4] Berinde, V. and Choban, M., Remarks on some completeness conditions involved in several common fixed point theorems, Creat. Math. Inform., 19 (2010), No. 1, 1-10

[5] Berinde, V. and Choban, M., Generalized distances and their associate metrics. Impact on fixed point theory, Creat. Math. Inform., 22 (2013), No. 1, 23-32

[6] Birkhoff, G., Lattice Theory, Providence, 1967

[7] Caristi,J., Fixed point theorems for mappings satisfying inwardness conditions, Trans. Amer. Math. Soc., 215 (1976), 241-251

[8] Cauty, R., Solution du probléme de point fixe de Schauder, Fund. Math., 170 (2001), 231-246

[9] Cauty, R., Un théorème de point fixe pour les fonctions multivoques acycliques, In: V. Kadets and W. Zelazko (editors), Functional Analysis and its Applications, Proceed. of the Intern. Conf. dedicated to 110th Anniversary of Stefan Banach, May 28-31, 2002, Lviv, Ukraine, Elsevier, 2004, 71-80

[10] Choban, M. M., Fixed points for mappings defined on pseudometric spaces, Creative Mathematics and Informatics, 22 (2013), No. 2, 173-184

[11] Choban, M. M., Fixed points for mappings defined on generalized gauge spaces, 5th Minisymposium on Fixed Point: Theory and Applications, june 1-7, 2014, Baia Mare and Turist Suior Resort, Romania, Abstracts, Baia Mare, 2014, 8-9

[12] Choban, M. M. and Calmutchi, L. I., Fixed points theorems in multi-metric spaces, Annals of the Academy of Romanian Scientists, Series on Mathematics and its Applications, 3 (2011) 46-68

[13] Choban, M. M. and Calmutchi, L. I., Fixed points theorems in E-metric spaces, ROMAI Journal, 6 (2010), No. 2, 83-91

[14] Engelking, R., General Topology, PWN. Warszawa, 1977

[15] Gelfand, I. M. Raikov, D. A. and Šilov, G. E., Commutative Normed Rings, Gos. Izd-vo Fiziko-Matem. Lit., Moskva, 1960 (in Russian), (English translation: Chelsea, New York, 1964)

[16] Granas, A., and Dugundji, J., Fixed point theory, Springer-Verlag, New York, 2003

[17] Iseki, K., On a Banach theorem on contractive mappings, Proceed. Japan Academy, 41 (1965), 145-146

Received: 29.09.2014; In revised form: 12.03.2015; Accepted: 15.03.2015

2010 Mathematics Subject Classification. 54H25, 54E15, 54H13, 12J17, 54E40.

Key words and phrases. Fixed point, pseudo-gauge structure, Banach metric scale, pseudometric . 
[18] Nedev, S. I. and Choban, M. M., A general concept of metrizability for topological spaces, Annuare Univers. Sofia, Facult. Math., 65 (1973), 111-165

[19] Rus, I. A., The theory of a metrical fixed point theorem: theoretical and applicative relevance, Fixed Point Theory, 9 (2008), 293-307

[20] Rus, I. A., Petrusel, A. and Petrusel, G., Fixed point theory, Cluj University Press, Cluj-Napoca, 2008

TIRASPOL STATE UNIVERSity

DePARTMENT OF Algebra, GeOMETRY AND TOPOlOGY

5 GH. IABlocikin STR., MD2069 CHIŞINĂU, Republic OF Moldova

E-mail address: mmchoban@gmail.com 